\title{
Environmental correlates of temporary emigration for female Weddell seals and consequences for recruitment
}

\author{
Glenn E. Stauffer,${ }^{1,3}$ Jay J. Rotella, ${ }^{1}$ Robert A. Garrott, ${ }^{1}$ and William L. Kendall ${ }^{2}$ \\ ${ }^{1}$ Department of Ecology, Montana State University, Bozeman, Montana 59717 USA \\ ${ }^{2}$ U.S. Geological Survey, Colorado Cooperative Fish and Wildlife Research Unit, Fort Collins, Colorado 80523 USA
}

\begin{abstract}
In colonial-breeding species, prebreeders often emigrate temporarily from natal reproductive colonies then subsequently return for one or more years before producing young. Variation in attendance-nonattendance patterns can have implications for subsequent recruitment. We used open robust-design multistate models and 28 years of encounter data for prebreeding female Weddell seals (Leptonychotes weddellii [Lesson]) to evaluate hypotheses about (1) the relationships of temporary emigration (TE) probabilities to environmental and population size covariates and (2) motivations for attendance and consequences of nonattendance for subsequent probability of recruitment to the breeding population. TE probabilities were density dependent $\left(\hat{\beta}_{\mathrm{BPOP}}=0.66, \widehat{\mathrm{SE}}=0.17\right.$; estimated effects $[\beta]$ and standard errors of population size in the previous year) and increased when the fast-ice edge was distant from the breeding colonies $\left(\hat{\beta}_{\text {DIST }}=0.75, \widehat{\mathrm{SE}}=0.04\right.$; estimated effects and standard errors of distance to the sea-ice edge in the current year on TE probability in the current year) and were strongly age and state dependent. These results suggest that trade-offs between potential benefits and costs of colony attendance vary annually and might influence motivation to attend colonies. Recruitment probabilities were greatest for seals that consistently attended colonies in two or more years (e.g., $\hat{\psi}_{\text {age } 10}=0.56, \mathrm{SD}=0.17$ ) and lowest for seals that never or inconsistently attended prior to recruitment (e.g., $\hat{\hat{\psi}}_{\text {age } 10}=0.32, \mathrm{SD}=0.15$ ), where $\hat{\hat{\psi}}_{\text {age } 10}$ denotes the mean recruitment probability (over all years) for 10-year-old seals for the specified prebreeder state. In colonial-breeding seabirds, repeated colony attendance increases subsequent probability of recruitment to the adult breeding population; our results suggest similar implications for a marine mammal and are consistent with the hypothesis that prebreeders were motivated to attend reproductive colonies to gain reproductive skills or perhaps to optimally synchronize estrus through close association with mature breeding females.

Key words: capture-mark-recapture; colonial breeding; density dependence; environmental variability; marine mammal; McMurdo Sound, Antarctica; open robust-design multistate; pinniped; Ross Sea; trade-offs; unobservable states.
\end{abstract}

\section{INTRODUCTION}

In long-lived colonial-breeding species, and some noncolonial, territorial species, it is common for juveniles to be absent from reproductive areas for one or several years postbirth or posthatching and to then subsequently attend these areas for a few years before recruiting (here recruitment refers to first production of offspring rather than first mating attempt) into the breeding population (e.g., Cadiou et al. 1994, Beauplet et al. 2005, Jenouvrier et al. 2008). When sampling occurs only at breeding sites, individuals are in an unobservable state when they are temporarily absent from those sites, and entry into or remaining in such a state is termed temporary emigration (TE; Kendall and

Manuscript received 18 October 2013; revised 14 February 2014; accepted 4 March 2014. Corresponding Editor: J. P. Y. Arnould.

${ }^{3}$ Present address: 419 Forest Resources Building, Pennsylvania State University, University Park, Pennsylvania 16802 USA. E-mail: ges162@psu.edu
Bjorkland 2001). In some species (e.g., Halley et al. 1995, Dittmann and Becker 2003), most prebreeders follow similar patterns of nonattendance/attendance, but in other species the number of years absent from breeding colonies or the number of years prebreeders attend colonies before recruiting varies considerably depending on characteristics of the individual or the environment (e.g., Beauplet et al. 2005, Jenouvrier et al. 2008). Understanding the causes and consequences of variation in temporary emigration is of considerable ecological interest given possible implications of attendance or nonattendance for age of recruitment or future reproductive success (Cam et al. 2002, Dittmann et al. 2007).

In several colonial-breeding species where TE by juveniles has been explicitly investigated, populationlevel TE probabilities vary considerably with individual- and population-level attributes (Beauplet et al. 2005, Jenouvrier et al. 2008, Stauffer et al. 2013a). TE probabilities typically decline with increasing age, possibly because older individuals have increased 
motivation or ability to navigate to colonies while avoiding potential costs of attendance related to limited foraging opportunities or intraspecific conflict at breeding colonies (Siniff et al. 1977, Furness and Birkhead 1984, Dittmann and Becker 2003). Variation in food supply or foraging opportunities driven by environmental conditions can influence growth rates or body condition of individuals (Madsen and Shine 2000), and thus individuals should be less likely to attend colonies when unfavorable conditions compromise body condition (Frederiksen and Bregnballe 2000, Jenouvrier et al. 2008). There is circumstantial evidence that TE probabilities might also be density dependent, although the mechanism is unknown (Rotella et al. 2009). Despite the prevalence of TE in the life history of most colonialbreeding species, rigorous estimation of TE probabilities, especially as a function of environmental and population- or individual-level covariates, remains rare in population studies.

One possible motivation for attendance at reproductive colonies by prebreeders is the opportunity to prospect for information or acquire reproductive skills by observing conspecifics. Possible prospecting behavior and consequent benefits has been investigated mostly in avian species, especially colonial seabirds (see review in Reed et al. [1999]). Prebreeders that attend colonies for multiple years are more likely to recruit and breed successfully than individuals attending colonies for the first time (Halley et al. 1995, Dittmann et al. 2007). The age of recruitment and the extent to which prebreeders practice breeding behavior have also been associated with subsequent breeding success (Cam et al. 2002). Prospecting Kittiwakes (Rissa tridactyla) sometimes squat on active nests temporarily unoccupied by the nest owners, and this behavior appears to facilitate future mate pairing or acquisition of nearby nest sites (Cadiou et al. 1994, Cam et al. 2002). Wandering Albatross (Diomedea exulans) spend 2-8 yr interacting with conspecifics at reproductive colonies before recruiting and frequently pair up with a reproductive partner $>1 \mathrm{yr}$ before making their first breeding attempt (Pickering 1989). Prospecting might thus inform decisions about where or even how to recruit, especially when prebreeders participate in behavior typically associated with reproduction. That is, attendance at reproductive colonies by prebreeders and observation of conspecifics might facilitate social learning (see review in Galef and Laland [2005]) and acquisition of social skills necessary for successful recruitment (Becker and Bradley 2007).

Some pinniped species also have a life history of prolonged absence of prebreeders followed by $\geq 1 \mathrm{yr}$ of colony attendance before recruitment (e.g., Beauplet et al. 2005, Hadley et al. 2006), but the implications of attendance for subsequent recruitment or breeding success are not as well documented in this group as for colonial seabirds. Prebreeders might benefit from observing pup births, interactions between mothers and pups during lactation, or when pups first begin to swim, or by observation of mating interactions and potential mate quality. Mate choice by females has been shown for Antarctic fur seals (Arctocephalus gazella; Hoffman et al. 2007) and is a common feature of lekking species (see review in Balmford 1991).

Unlike birds, pinnipeds have long gestation periods such that individuals producing young in a given year must mate in the previous year. Reproductive colonies are foci of mating activity, and thus another possible motivation for colony attendance by female prebreeders is initiation or synchronization of estrus cycles by close association with reproductive adult females. Such synchronization occurs in several mammalian taxa, including humans (McClintock 1978, Handelmann et al. 1980, Stern and McClintock 1998). Although some seals likely mate while absent from reproductive colonies (de Bruyn et al. 2011), attending reproductive colonies might increase the probability that first-time estrus is optimally timed.

We used 28 yr (1983-2010) of capture-mark-recapture data for female prebreeders from a population of Weddell seals (Leptonychotes weddellii) breeding in Erebus Bay, Antarctica to investigate (1) correlates of variability in age-specific TE probabilities in prebreeders and (2) possible motivations for attendance and consequences of nonattendance for recruitment probabilities. TE and recruitment probabilities in this population are highly variable (Hadley et al. 2006, Stauffer et al. 2013a), and annual environmental conditions in and around Erebus Bay also are highly variable. Multiple decades of encounter data are available for individually marked seals, and because seals are easily approached, they are highly detectable and reproductive status can be reliably identified. We evaluated support for (1) the hypothesis that age-specific probability of TE is related to variability in the environment, local population size, or both and (2) the nonexclusive hypotheses that attendance by prebreeders is motivated by opportunities to gather information or acquire skills, or to facilitate timing or onset of estrus. We operationally defined a prebreeder as any female individual that had not yet produced her first pup, even though she may have mated. Consequently, we defined recruitment as first reproduction of offspring rather than first mating attempt.

\section{Methods}

\section{Study area and population}

Erebus Bay is located on the western side of Ross Island in McMurdo Sound, Antarctica. Approximately 300-600 Weddell seal pups are born on the ice surface each austral spring at several areas throughout Erebus Bay where tidal action and glacial pressures on fast ice result in perennial sea-ice cracks that provide reliable access to the surface of the fast ice (Stirling 1969, Siniff et al. 1977). Females give birth to a single pup after a gestation period of about 11 months, including about 
two months of diapause, and then primarily use stored reserves to sustain a period of lactation and close association with the pup (see Plate 1) lasting about 3045 d (Smith 1966, Hill 1987). Males defend mating territories under the ice, where mating takes place near the end of the pupping season (Siniff et al. 1977, Hill 1987).

Food resources for seals are probably limited in Erebus Bay (Testa et al. 1985), and adults and pups are believed to move out into food-rich foraging areas in the southwest Ross Sea following the pupping season (Smith 1965, Burns et al. 1999, Stewart et al. 2000). Females born in Erebus Bay typically emigrate temporarily for $\geq 1 \mathrm{yr}$ following birth, then attend reproductive colonies in Erebus Bay for $\geq 1$ yr (but not always in consecutive years) before recruiting into the pupproducing portion of the population (Hadley et al. 2006, Cameron et al. 2007, Stauffer et al. 2013a). Despite the fact that female Weddell seals physiologically can reproduce by age $2-4$ yr (Smith 1966), the mean age at first reproduction is estimated as $7.6 \mathrm{yr}$ (Hadley et al. 2006).

\section{Data collection}

In this study, we used data from 5550 female Weddell seals tagged as pups in Erebus Bay during the pupping seasons of 1983-2010. During these years, nearly all pups born in Erebus Bay were individually marked with a pair of tags in the interdigital webbing of each hind flipper (four identical tags total); broken or missing tags on adults were subsequently replaced as necessary. Consequently, a large percentage of the females in Erebus Bay each year were individually identifiable and of known age. Resighting data primarily included observations from five-to-eight intensive surveys conducted during early November through mid-December in Erebus Bay each year (3-6 d between surveys). To maximize detection probability, we also included observations within Erebus Bay from the $2-3$ d preceding and following each intensive survey. Detections occurred only within the Erebus Bay study area, the boundaries of which remained consistent each year. We assumed that mothers born within the study area produced their own pups within the study area, and in Discussion we address possible violation of this assumption.

\section{Covariates of temporary emigration}

We considered the following covariates of TE: (1) winter sea ice extent (SIE) for the Ross Sea sector measured in September of year $t$ just before the pupping season; (2) Southern Oscillation Index (SOI) averaged for the winter (July-September) in year $t$; (3) sea-ice concentration (SIC) averaged over eight $25-\mathrm{km}$ grid cells in and around McMurdo Sound for November of year $t$; (4) shortest distance (DIST) from the study area to an open water polynya at the edge of the fast ice during the breeding season of year $t$; and (5) the size of the breeding population of females (BPOP) in year $t-1$. Note that
SIE and DIST are uncorrelated because the distance to the polynya at the edge of the fast ice is independent of the extent of pack ice beyond the polynya. Winter sea ice is important in the life cycle of krill (Loeb et al. 1997), and increased krill abundance may benefit Antarctic silverfish (Pleurogramma antarcticum), a primary food source for Weddell seals (Burns et al. 1998). Additionally, Weddell seals, given their excellent diving abilities (Castellini et al. 1992), probably are better able to exploit resources under extensive ice sheets than are other Antarctic predators, and extensive winter sea ice may reduce competition for prey. Thus, food resources in the Ross Sea should be most plentiful when sea ice is extensive. SOI is a broadscale climatic index commonly used as a measure of $\mathrm{El} \mathrm{Niño/Southern} \mathrm{Oscillation}$ (ENSO) strength in the southern Ocean. SOI is positively correlated with sea ice extent in the Ross Sea (Kwok and Comiso 2002), and positive SOI phases have been linked to increases in seal pup weaning mass, population size, and reproductive rates (Testa et al. 1991, Proffitt et al. 2007, Rotella et al. 2009). We predicted decreased TE probabilities associated with SIE or positive SOI phases because seals should be in good condition and more likely to forego foraging opportunities while attending colonies when resources are plentiful. We expected SIC and DIST to influence access to reproductive colonies by determining the distance seals have to swim under ice to reach haul-out areas in Erebus Bay. Thus we predicted a positive relationship between TE and DIST or SIC. Lastly, given the suggestion by Rotella et al. (2009) that TE probabilities of adult female Weddell seals might be density dependent, we predicted a positive relationship between TE and BPOP.

SIE and SIC data were obtained from the National Snow and Ice Data Center and SOI data from the Australian Government, Bureau of Meteorology SOI Archive (data available online). ${ }^{4,5}$ DIST was measured from georeferenced satellite images dated as close as possible to 1 November. Images were not available for all years so we used multiple imputation methods (Schafer 1999) to evaluate the influence of DIST on TE probabilities (details in Appendix A). Environmental covariates were standardized (mean $=0, \mathrm{SD}=1)$, and population sizes were log-transformed in all analyses.

\section{Data analysis}

We used open robust-design multistate (ORDMS; Kendall and Bjorkland 2001, Kendall 2004) models to estimate transition probabilities (denoted with the symbol $\psi$ ) of Weddell seals between seven demographic states (see Appendix A for full modeling details). We defined the seven states (Appendix A: Fig. A1) as P0 (pup); U0 (unobservable prebreeder, never previously observed in Erebus Bay subsequent to birth); P1 (first-

\footnotetext{
$4 \mathrm{ftp}: / /$ sidads.colorado.edu/pub/DATASETS/

${ }^{5}$ www.bom.gov.au/climate/current/soihtm1.shtml
} 
time observable prebreeder); U1 (unobservable prebreeder, previously observed once); P2 (observable prebreeder, previously observed $\geq 1$ time); U2 (unobservable prebreeder, previously observed $\geq 2$ times); and F (observable first-time mother). TE was defined as a transition into any of the unobservable states (e.g., $\psi^{\text {P0U0 }}$ denoted transition probability from pup to unobservable prebreeder) and recruitment as a transition into state $\mathrm{F}$ (e.g., $\psi^{\mathrm{P} 1 \mathrm{~F}}$ denotes recruitment probability from state P1). Our goal was to investigate possible sources of variation in transition probabilities of prebreeders, so we right-censored information for seals after they recruited. Censoring simplified the analysis by limiting the number of possible state transitions and was justified by the near-perfect detection of mothers within Erebus Bay (Hadley et al. 2006, Stauffer et al. 2013a).

Based on previous analyses (Hadley et al. 2006, Stauffer et al. 2013a), we estimated TE for 11 nominal age classes $(1,2,3,4,5,6,7,8,9,10$, and $\geq 11$ yr old $)$ and recruitment for eight nominal age classes (4, 5, 6, 7, $8,9,10$, and $\geq 11$ yr old), where age denotes a female's age class at the end of an interval. For example, $\psi_{t, \text { age } 5}^{r z}$ denotes the probability of transition from state $r$ at age 4 $\mathrm{yr}$ in year $t-1$ to state $z$ at age $5 \mathrm{yr}$ in year $t$. We fixed to zero all transitions that were impossible based on our state structure and knowledge of the earliest possible age of recruitment.

To evaluate which covariates best explained TE probabilities, we constructed 17 models that estimated age-specific TE as logit-linear functions of covariates. Our model set included all possible combinations of covariates with the constraint that we did not allow SIE and SOI or SIC and DIST to appear in the same model because of pairwise correlations $>0.4$ for these pairs and the a priori hypothesis of similar effects of these covariates. In each of these models, we allowed state dependency in TE and recruitment probabilities based on whether or not females attended a reproductive colony in year $t-1$. For recruitment probabilities, we also included an additive year effect (year effects shared across all ages and states). We compared estimated TE probabilities from our best covariate model to estimates from two baseline models that either included an additive year effect unstructured by covariates (year model) or specified equal TE rates for all years (null model).

To evaluate hypotheses about motivations for attendance by prebreeders and consequences for age-specific recruitment, we constructed a suite of four models with different state-dependent structures for recruitment probabilities. The first structure modeled recruitment as equal for all states and represented the null hypothesis that attendance patterns have little consequence for subsequent recruitment. The second structure modeled recruitment probabilities in year $t$ based on whether a seal attended a reproductive colony in year $t-1$ but ignored attendance information for years before $t-1$; this structure represented the estrus hypothesis that motivation to attend colonies is related to facilitation of optimal timing of estrus in prebreeders. Embryonic diapause synchronizes reproduction in pinnipeds (Boyd 1991), with consequent synchrony in ovulation and presumably mating (Smith 1966, Hill 1987). Mating synchrony might be advantageous if it allows most females to mate with dominant males (Wartzok 1991). Such advantages would be greatest for highly polygynous species, but might also be important for moderately polygynous Weddell seals where males defend underwater territories (Siniff et al. 1977, Hill 1987). Also, spermatogenesis in Weddell seals declines shortly after the breeding season (Smith 1966), so females that ovulate late might fail to mate successfully. Given that prebreeders do not have a previous parturition to trigger estrus, we suggest that close association with parous females could provide chemical or social cues to trigger timely ovulation. Therefore, we predicted greater recruitment probabilities for observable than unobservable prebreeders. To represent the experience hypothesis that attendance was motivated by opportunities to acquire information or skills, the third structure modeled recruitment probabilities based on whether seals had attended a reproductive colony in $\geq 2 \mathrm{yr}$, but ignored information on when attendance occurred. Given that the mean age of physiological sexual maturity is considerably younger than the mean age at recruitment (Smith 1966, Hadley et al. 2006), it seems clear that there are other factors, perhaps behavioral, that influence recruitment probability. The experience hypothesis posits that repeated attendance at reproductive colonies facilitates observation and learning of appropriate behavior that increases the probability of successful subsequent mating. Thus recruitment probability should be greatest for individuals that attended at least twice (e.g., $\psi^{\mathrm{P} 2 \mathrm{~F}} \approx \psi^{\mathrm{U} 2 \mathrm{~F}}>\psi^{\mathrm{P} 1 \mathrm{~F}} \approx \psi^{\mathrm{U} 1 \mathrm{~F}}$ ). Our fourth model structure estimated different recruitment rates for each state and represented the hypothesis that synchronization of estrus and acquisition of experience both might motivate attendance. In each model, annual variation for transition probabilities was unstructured (not a function of environmental covariates) with patterns shared across age classes. Model structures for survival probabilities and parameters representing within-year dynamics (see Appendix A for details) were based on previous analyses (Hadley et al. 2006, Rotella et al. 2009, Stauffer et al. 2013b).

We performed analyses in program MARK (White and Burnham 1999) through the RMark package (Laake 2013) in program $\mathrm{R}$ ( $\mathrm{R}$ Development Core Team 2012). Currently there is no general goodness-offit test for the type of ORDMS models we used in our analysis, and the median $\hat{c}$ procedure implemented into program MARK ( $\hat{c}$ is an estimated overdispersion parameter) is not available for robust design data. Thus, we used Akaike information criterion corrected for small sample sizes $\left(\mathrm{AIC}_{\mathrm{c}}\right)$ rather than quasi-likelihood 
$\mathrm{AIC}_{\mathrm{c}}\left(\mathrm{QAIC}_{\mathrm{c}}\right)$ as our model selection criterion. However, we did assess the influence of possible overdispersion on model-selection results by examining how model rankings based on $\mathrm{QAIC}_{\mathrm{c}}$ changed as we increased $\hat{c}$ (Appendix B: Table B1).

\section{RESULTS}

Of the 5550 female seals in our data set, 1333 were observed as prebreeders in $\geq 1 \mathrm{yr}$ after tagging, and 942 recruited into the study area's breeding population (mean age at first reproduction was 7.7, range of 4-16 yr) by 2010. Most females were present by the first survey period each year, and the probability of being detected at least once during each season was $\geq 0.91$ for prebreeders and $>0.99$ for pups and mothers (details in Appendix A). Between the year when they were born and the year when they gave birth to their first pup, 246 females ( $26 \%$ of first-time breeders) were never observed in the breeding colonies as prebreeders (mean age at first reproduction was 7.0, range of 4-15 yr), 278 (30\%) were observed as prebreeders in $1 \mathrm{yr}$ (mean age at first reproduction was 7.5, range of 5-13 yr), and 418 (44\%) were observed as prebreeders in $>1 \mathrm{yr}$ (mean age at first reproduction was 8.3 , range of $5-16 \mathrm{yr}$ ). For seals that were observed as prebreeders, mean age at first observation was $4.6 \mathrm{yr}$ (range of 1-12 yr) and mean observed number of years of attendance was 2.1 (range of $1-5 \mathrm{yr})$.

As expected, TE probabilities were strongly age- and state-dependent. Consistent with the hypothesis that highly variable environmental conditions should influence motivation or ability of prebreeders to attend colonies, year-to-year variability in TE probabilities was substantial, particularly after 2000 (Fig. 1a, c). Our bestsupported covariate model (Table 1, model 9) supported our predictions that TE probabilities would be greatest when the current-year fast-ice edge was distant $\left(\hat{\beta}_{\text {DIST }}=\right.$ $0.76, \widehat{\mathrm{SE}}=0.04$; estimated effects $[\beta]$ and standard errors of distance to the sea-ice edge in the current year on TE probability in the current year) and when the previous year's population of adult seals was large $\left(\hat{\beta}_{\mathrm{BPOP}}=0.66\right.$, $\widehat{\mathrm{SE}}=0.17$; estimated effects and standard errors of population size in the previous year). Annual variation in DIST and BPOP was considerable and was strongly related to predicted TE probabilities (Fig. 1b,d). For example, in a year when DIST was minimal and the previous year's BPOP was small, predicted TE probability was $0.40(\widehat{\mathrm{SE}}=0.04)$ for a 5 -yr-old seal that did not attend a reproductive colony in the previous year. In contrast, predicted TE probability was $0.91(\widehat{\mathrm{SE}}=0.01)$ in a year when DIST was maximal and BPOP was large. These covariates appear to explain much of the annual variation in TE probabilities: estimated TE probabilities from our best-supported covariate model were similar in most years to those from a more general model with unstructured annual variation in TE probabilities (Fig. 1c). Our second and third best-supported models included BPOP and DIST, with estimated coefficients and annual TE estimates similar to those from the top model, but also included either SIE or SOI as predictors. However, estimated effect sizes were essentially zero $\left(\hat{\beta}_{\mathrm{SIE}}=0.04, \widehat{\mathrm{SE}}=0.03 ; \hat{\beta}_{\mathrm{SOI}}=0.005, \widehat{\mathrm{SE}}=0.04\right)$ and model deviance improved little (Table 1). Thus, SIE and SOI apparently explained little additional variation in TE probabilities beyond that explained by BPOP and DIST.

Estimates from the year model (Table 1, model 21) indicated that TE probabilities were high for 1-yr-olds $\left(\overline{\hat{\psi}}_{t, \text { age } 1}^{\mathrm{POU}}=0.98, \widehat{\widehat{\mathrm{SE}}}=0.01, \mathrm{SD}\left[\hat{\psi}_{t, \text { age } 1}^{\mathrm{POUO}}\right]=0.019\right)$, subsequently decreased until age eight (e.g., $\overline{\hat{\psi}}_{t, \text { age } 8}^{\mathrm{PlU}}=$ $\left.0.15, \widehat{\widehat{\mathrm{SE}}}=0.02, \mathrm{SD}\left[\hat{\psi}_{t \text {,age8 }}^{\mathrm{PlU1}}\right]=0.16\right)$, then gradually increased for the older age classes (e.g., $\overline{\hat{\psi}}_{t, \text { age } 11+}^{\mathrm{Pl} 1}=0.29$, $\widehat{\widehat{\mathrm{SE}}}=0.05, \mathrm{SD}\left[\hat{\psi}_{t, \text { age } 11+}^{\mathrm{PlU1}}\right]=0.22 ;$ Fig. 1a). Symbols with a circumflex denote estimated parameters, and overbars denote parameter estimates averaged over all years. As predicted, seals that did not attend a reproductive colony in year $t-1$ had higher TE probabilities than seals that did attend $\left(\hat{\beta}_{\text {attend }}=-1.35, \widehat{\mathrm{SE}}=0.10,95 \% \mathrm{CI}\right.$ $=-1.54$ to -1.15 ; e.g., $\widehat{\hat{\psi}}_{t, \text { age8 }}^{\mathrm{U} 2 \mathrm{U} 2}-\hat{\psi}_{t, \mathrm{age} 8}^{\mathrm{P2U} 2}=0.21, \widehat{\widehat{\mathrm{SE}}}=$ $0.024)$.

Our best-supported model in the recruitment suite (Table 1) represented the hypothesis that both synchrony of estrus and acquisition of information might motivate colony attendance. This model allowed different age-specific recruitment probabilities for each prebreeder state and indicated strong age and time dependence (Fig. 2) but provided mixed support for both hypotheses. As predicted, observable prebreeders were more likely to recruit than were unobservable prebreeders, given that both had attended colonies in two or more previous years (e.g., $\overline{\hat{\psi}_{t, \text { age }}^{\mathrm{P} F}-\hat{\psi}_{t, \mathrm{age} 8}^{\mathrm{U} 2 \mathrm{~F}}}=0.19$, $\widehat{\mathrm{SE}}=0.05)$. However, this difference was not evident for prebreeders that had only attended colonies in one previous year (e.g., $\overline{\hat{\psi}}_{t, \text { age } 8}^{\mathrm{PlF}}-\hat{\psi}_{t, \text { age } 8}^{\mathrm{U1F}}<0.01, \overline{\widehat{\mathrm{SE}}}=0.038$ ). Among observable prebreeders, those with more years of colony attendance were most likely to recruit (e.g., $\left.\overline{\hat{\psi}_{t, \text { age } 8}^{\mathrm{P} F}-\hat{\psi}_{t, \text { age } 8}^{\mathrm{PIF}}}=0.11, \overline{\widehat{\mathrm{SE}}}=0.033\right)$. Previous colony experience seemed less important for seals that were unobservable the year prior to recruitment. Unobservable prebreeders that attended in one previous year were slightly more likely to recruit than seals that had no previous colony experience (e.g., $\overline{\hat{\psi}}_{t, \text { age8 }}^{\mathrm{U1F}}-\hat{\psi}_{t, \text { age }}^{\mathrm{U} \text {. }}=0.08$, $\widehat{\widehat{\mathrm{SE}}}=0.03$ ), but additional years of colony experience did not increase age-specific recruitment probabilities further (e.g., $\overline{\hat{\psi}_{t, \text { age }}^{\mathrm{U} F}-\hat{\psi}_{t, \text { age }}^{\mathrm{U1F}}}=-0.08, \overline{\widehat{\mathrm{SE}}}=0.05$ ). Average recruitment probability was $<0.01$ for seals at age four, remained low $(<0.1)$ for seals at age five, gradually increased to a maximum at age 10 (e.g., $\hat{\psi}_{t, \text { age } 10}^{\mathrm{P} 2 \mathrm{~g}}=0.56$, $\left.\widehat{\widehat{\mathrm{SE}}}=0.06, \mathrm{SD}\left[\hat{\psi}_{t, \mathrm{age} 10}^{\mathrm{P} 2 \mathrm{~F}}\right]=0.17\right)$, and then declined slightly in the oldest age class (e.g., $\overline{\hat{\psi}}_{\text {t.age11+ }}^{\mathrm{P} 2 \mathrm{~F}}=0.41, \widehat{\widehat{\mathrm{SE}}}=0.06$, $\mathrm{SD}\left[\hat{\psi}_{t, \mathrm{age} 11+}^{\mathrm{P} F}\right]=0.16$; Fig. 2a). Recruitment probabilities 

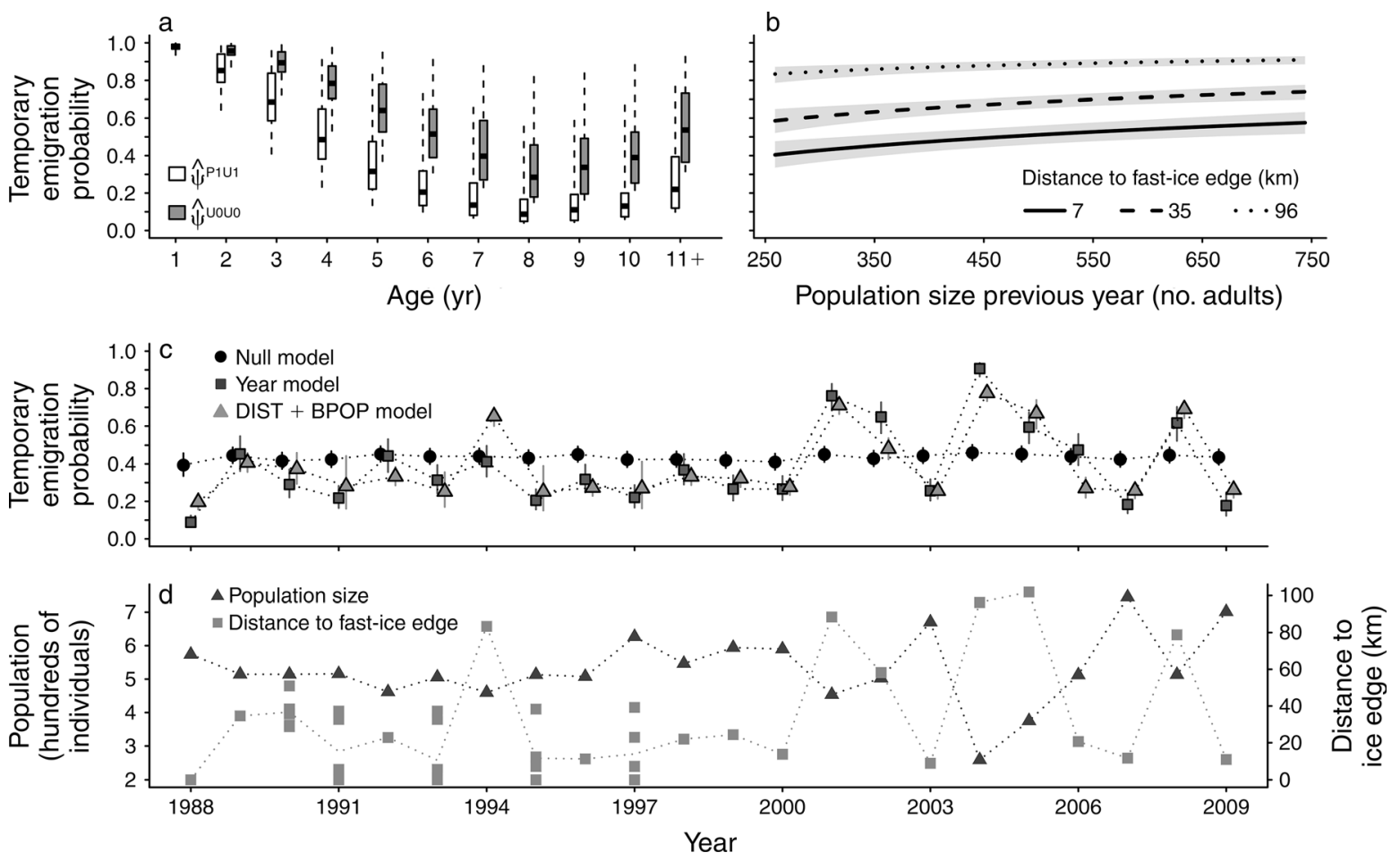

FIG. 1. Annual covariate values and temporary emigration (TE) rates of female prebreeder Weddell seals in Erebus Bay, Antarctica. (a) Summary of annual TE rates estimated from year model (unstructured annual variation; Table 1, model 21) with medians (dark bars), interquartile range (boxes), and whiskers bounding the 2.5th and 97.5th percentiles of annual point estimates; $\hat{\psi}^{\mathrm{U} O \mathrm{U} 0}$ denotes TE by seals never observed as prebreeders, $\hat{\psi}^{\mathrm{P} 1 \mathrm{U} 1}$ denotes first-time observable prebreeder $(\mathrm{P} 1)$ or unobservable prebreeder, previously observed once (U1), where $\hat{\psi}$ denotes estimated transition probability. (b) Predicted TE rates (point estimates and $95 \%$ confidence intervals [CIs] for $\hat{\psi}_{t, \text { age } 5}^{\mathrm{U} \text {, w }}$, where $\hat{\psi}_{t, \text { age } 5}^{\mathrm{U1} 1}$ indicates TE by seals previously observed once as prebreeders, but not in the previous year, where $t$ is year and age5 is age of seal) when distance to the fast-ice edge is close (solid line), intermediate (dashed line), or far (dotted line), over a range of population sizes. Estimates were generated from the best-supported

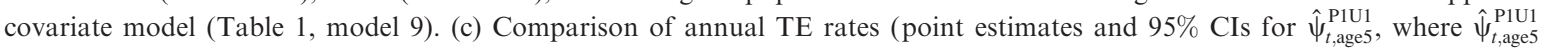
indicates first-time observable prebreeders) estimated from null model, year model, and best covariate model. (d) Annual breeding population size in Erebus Bay and distance to fast ice. Distance values in some years represent multiple imputations of missing values for those years; the line passes through the mean of imputed values.

TABLE 1. Models representing hypotheses about variation in transition probabilities for female Weddell seals in Erebus Bay, Antarctica.

\begin{tabular}{|c|c|c|c|c|c|}
\hline Model & $K$ & $\mathrm{AIC}_{\mathrm{c}}$ & $\Delta \mathrm{AIC}_{\mathrm{c}}$ & $w_{i}$ & Deviance \\
\hline \multicolumn{6}{|l|}{ TE model suite } \\
\hline$\left(\right.$ Model 9) $\psi_{(a)}^{r \mathrm{~F}}, \psi_{(\mathrm{BPOP}+\mathrm{DIST})}^{r \mathrm{U}}$ & 87 & 74019.53 & 0.000 & 0.472 & 73845.15 \\
\hline (Model 17) $\psi_{(a)}^{r \mathrm{~F}}, \psi_{(\mathrm{BPOP}}^{r \mathrm{U}}$ DIST $\left.+\mathrm{SIE}\right)$ & 88 & 74020.11 & 0.587 & 0.352 & 73843.72 \\
\hline$\left(\right.$ Model 15) $\psi_{(a)}^{r \mathrm{~F}}, \psi_{(\mathrm{BPOP}+\mathrm{DIST}+\mathrm{SOI})}^{r \mathrm{U}}$ & 88 & 74021.51 & 1.985 & 0.175 & 73845.12 \\
\hline \multicolumn{6}{|l|}{ Recruitment model suite } \\
\hline$\left(\right.$ Model 22) $\psi_{(a e)}^{r \mathrm{~F}}, \psi_{(\text {year })}^{r \mathrm{U}}$ & 113 & 73685.08 & 0.000 & 0.976 & 73458.43 \\
\hline$\left(\right.$ Model 20) $\psi_{(e)}^{r \mathrm{~F}}, \psi_{(\text {year })}^{r \mathrm{U}}$ & 110 & 73692.66 & 7.580 & 0.022 & 73472.05 \\
\hline$\left(\right.$ Model 21) $\psi_{(a)}^{r \mathrm{~F}}, \psi_{(\text {year })}^{r \mathrm{U}}$ & 110 & 73699.01 & 13.935 & 0.001 & 73478.40 \\
\hline$\left(\right.$ Model 19) $\psi_{(\text {non-Markovian })}^{r \mathrm{~F}}, \psi_{(\text {year })}^{r \mathrm{U}}$ & 109 & 73699.57 & 14.492 & 0.001 & 73480.97 \\
\hline
\end{tabular}

Notes: In the temporary emigration (TE) model suite, rankings were robust for $\hat{c} \leq 3.5$, and in the recruitment model suite, the top model retained its rank for $\hat{c}<2.3$, where $\hat{c}$ is an estimated overdispersion parameter. See Appendix B: Table B1 for a table of complete model selection results for $\mathrm{TE} . \mathrm{AIC}_{\mathrm{c}}$ is Akaike's information criterion. Models included 11 nominal age classes $(1,2,3$, $4,5,6,7,8,9,10$, and $11+)$ for TE $\left(\psi^{r \mathrm{U}}\right)$ and annual variation and nine nominal age classes $(1-3,4,5,6,7,8,9,10$, and $11+)$ for recruitment $\left(\psi^{r \mathrm{~F}}\right)$, where $\psi^{r \mathrm{U}}$ is temporary emigration and $\psi^{r \mathrm{~F}}$ is recruitment. The Markovian structure for TE specified different rates depending on colony attendance the preceding year, whereas the Markovian structure for recruitment in the recruitment model suite specified dependence on either colony attendance $(a)$, previous attendance experience at time of recruitment $(e)$, both (ae), or neither (non-Markovian). Covariate values for TE were distance from Erebus Bay to the edge of the fast ice (DIST), population size of breeding female seals in the previous year (BPOP), winter sea ice extent (SIE), and Southern Oscillation Index (SOI). 

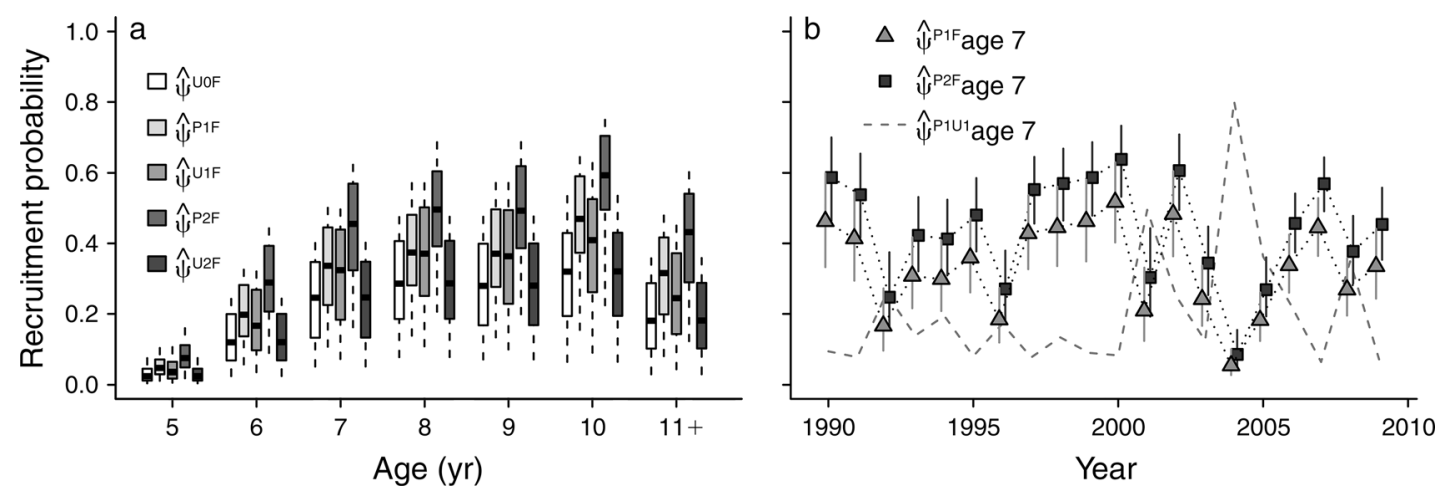

FIG. 2. Recruitment probabilities of female Weddell seals in Erebus Bay, Antarctica, estimated from the best-supported recruitment model (Table 1, model 22). Presented are (a) a summary of probabilities with medians (dark bars), the interquartile range (boxes), and whiskers bounding the 2.5th and 97.5th percentiles of annual point estimates; and (b) annual rates and 95\% confidence intervals for age 7 showing the temporal patterns shared by all ages and states in the model. In panel $b$, the dashed line indicating temporary emigration (TE) by first-time prebreeders $\left(\hat{\psi}^{\mathrm{P} 1 \mathrm{U} 1}\right)$ is included to illustrate the strong inverse correlation between recruitment and TE. The symbols $\hat{\psi}^{\mathrm{U} 0 \mathrm{~F}}, \hat{\psi}^{\mathrm{P} 1 \mathrm{~F}}, \hat{\psi}^{\mathrm{U} 1 \mathrm{~F}}, \hat{\psi}^{\mathrm{P} 2 \mathrm{~F}}$, and $\hat{\psi}^{\mathrm{U} 2 \mathrm{~F}}$, respectively, denote recruitment by seals never observed as prebreeders, observed for the first time in the previous year, observed once but not in the previous year, observed for at least the second time in the previous year, and observed at least twice, but not in the immediate previous year (where $\hat{\psi}$ denotes estimated transition probability).

were variable among years and tended to be low when TE probabilities were high (Fig. 2b).

\section{DisCUSSION}

We fit multistate capture-mark-recapture models to $28 \mathrm{yr}$ of encounter data for Weddell seals to evaluate possible correlates of annual variation in age-specific TE probabilities and implications of colony attendance and nonattendance for age-specific recruitment probabilities. Temporary emigration probabilities varied considerably from year to year, and our results are consistent with previous suggestions that such variation could be related to colony access, population size, or body condition (Rotella et al. 2009, Stauffer et al. 2013a). Our results also provide mixed support for the hypotheses that attending colonies for $\geq 1$ yr allows prebreeders to optimally time estrus or to acquire information or skills that increase subsequent age-specific recruitment probabilities.

The distance from Erebus Bay to open water varied annually from $<10 \mathrm{~km}$ to $>80 \mathrm{~km}$ (Fig. 1d), and, as expected, distance to the edge of the fast ice was strongly and positively related to TE probabilities. In years when fast ice is extensive, it likely is difficult for younger or smaller seals to gain access to Erebus Bay. Older and heavier Weddell seals have better diving abilities than younger and lighter seals, and diving behavior of young seals is subject to physiological or morphological constraints (Kooyman 1966, Burns 1999). Thus, a long swim under extensive fast ice might restrict access to Erebus Bay for prebreeders in poor physiological condition. If prebreeders need to learn to navigate to their natal sites, as has been anecdotally suggested for the colonial-breeding seabird Common Tern (Sterna hirundo; Dittmann and Becker 2003), then extensive fast ice might make navigation difficult for young seals.
There is a possible alternative explanation for the relationship between TE and DIST. Weddell seals are vulnerable to predation from orcas (Orcinus orca; Pitman and Durban 2012), but are safe from predation when hauled out on fast ice. Thus, in years when fast ice is minimal (DIST is small), more seals might be motivated to attend areas with reliable fast ice around Erebus Bay colonies, whereas when DIST is maximal there are large areas of predator-safe fast ice outside Erebus Bay. Until large numbers of seals are tracked outside Erebus Bay, it will be difficult to separate various motivations for prebreeders to attend reproductive colonies in Erebus Bay. It is likely that predator avoidance is one motivation, but there are reasons we believe that acquisition of information or social skills might provide additional motivation.

We do not know the underlying reasons for observed density dependence in TE probabilities, but suggest three nonexclusive hypotheses: (1) emigration is motivated by resource depletion related to large populations (see review in Matthysen 2005); (2) large local populations of adults in breeding colonies increase the level of social conflict between adults and prebreeders (Siniff et al. 1977), thus discouraging attendance (increasing motivation for TE) by prebreeders the following year; and (3) observed density dependence in TE probabilities is spurious (i,e., an artifact based on unmodeled correlations). Mature females generally do not forage extensively during the breeding season, but some resource depletion apparently does occur in Erebus Bay during the pupping season (Testa et al. 1985). When the number of seals in Erebus Bay colonies is large, the broader regional population might also be large if broadscale environmental conditions drive dynamics. However, that relationship is unknown to us. If true, consequent broadscale competition for resources in 


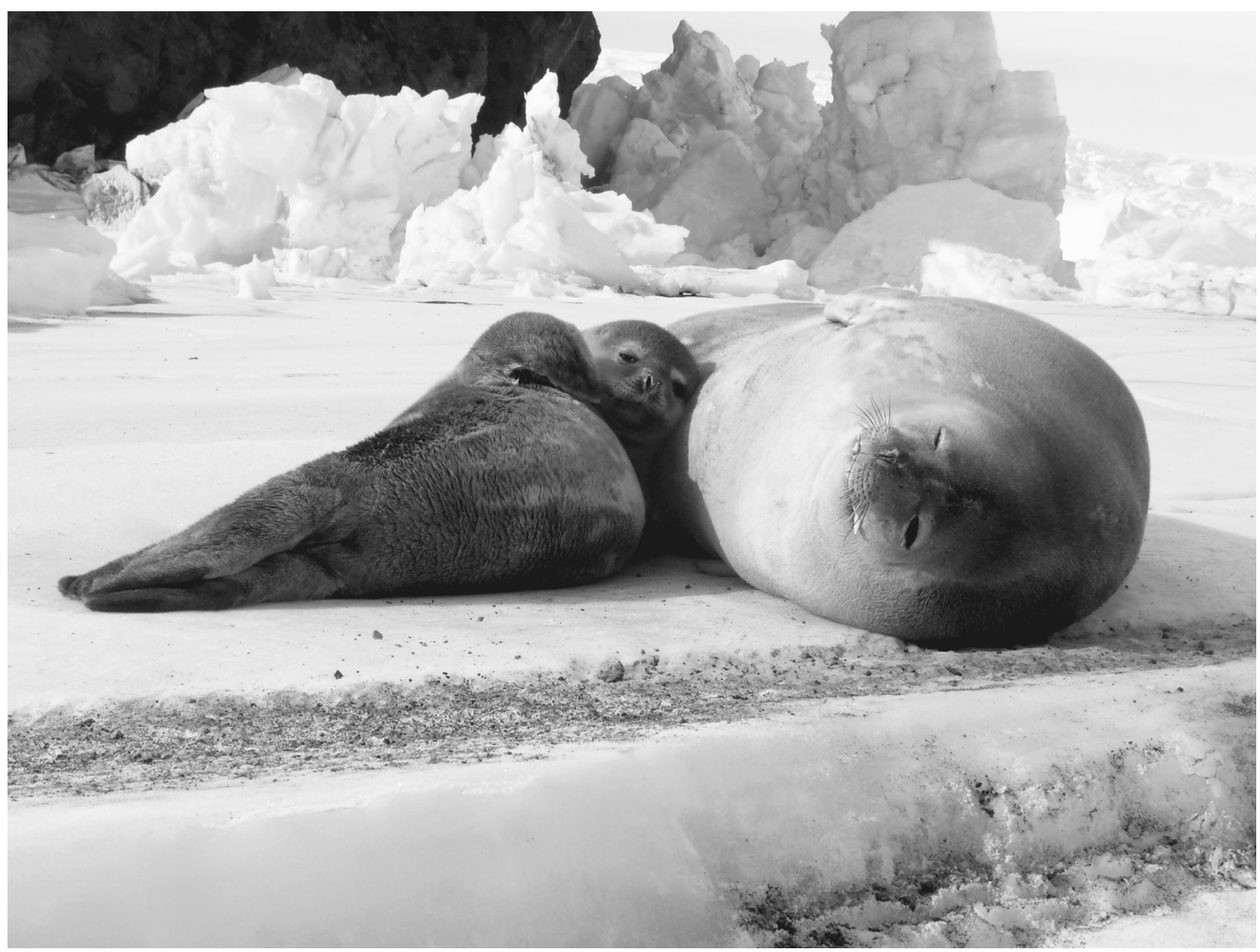

Plate 1. A Weddell seal mother and pup rest on the ice surface in Erebus Bay, Antarctica. Photo credit: Shawn C. Farry.

major foraging areas could be intense and negatively influence a seal's condition and motivation to attend breeding colonies. Given the potential of high-resolution satellite imagery for assessing regional population size (LaRue et al. 2011), it might soon be possible to address this hypothesis. Crowding of seals at the local scale appears to increase levels of conflict between individuals, and prebreeders are found mostly in the periphery of the reproductive colonies early in the breeding season (Stirling 1969, Siniff et al. 1977). Intrasexual aggression has also been documented in several other pinniped species (e.g., McCann 1982, Fernández-Juricic and Cassini 2007) and in some ungulates appears to motivate natal dispersal (e.g., Long et al. 2008). Proposing that intrasexual conflict in one year motivates TE the next year does assume either physiological costs or psychological influences that decrease ability or motivation to attend Erebus Bay the next year. The possibility remains that the density dependence we estimated in TE probabilities might be spurious. For example, population size may be correlated with environmental conditions. If favorable environmental conditions tend to be followed by less favorable conditions, then a large population size in one year would tend to be followed by a smaller population size and increased TE in the following year. Consequently, the apparent relationship between BPOP and TE might derive from correlated TE probabilities of prebreeders and adult seals (those already recruited into the breeding population), both driven by the same environmental factors. Analyses currently in progress to estimate TE probabilities of adult seals should provide insights about possible correlations between TE probabilities of adults and prebreeders.

Our results provided mixed support for the estrus and experience hypotheses, but the overall picture is one where age-specific recruitment probabilities were greatest for seals that consistently attended colonies, which is consistent with both hypotheses. On the one hand, seals that attended in the preceding year and $\geq 1$ additional previous year were more likely to recruit than seals that attended in only the preceding year (e.g., $\hat{\psi}_{t, \text { age }}^{\mathrm{P} 2 \mathrm{~F}}>\hat{\psi}_{t, \mathrm{age}}^{\mathrm{PlF}}$ ) or seals that attended in a previous year, but then subsequently skipped attendance (e.g., $\hat{\psi}_{t, \mathrm{age}}^{\mathrm{P} 2}>\hat{\psi}_{t, \mathrm{age}}^{\mathrm{U} 2 \mathrm{~F}}$ ). Weddell seals have a breeding system similar to lekking, where males defend underwater territories focused on cracks in the ice (Siniff et al. 1977). In such a system, prebreeders that attend Erebus Bay might benefit from observing mating behavior of mature seals, either gaining experience in evaluating potential mates or simply copying the behavior of other females (e.g., Dugatkin and Godin 1993, Valone 2007). The experience hypothesis is further supported by the observed difference between age at physiological maturity in female Weddell seals (2-4 yr; Smith 1966) and the average age at which females actually produce their first pup (7.6 yr; Hadley et al. 2006). There is also evidence for selective pressure for synchronized birth dates in 
Weddell seals and other pinnipeds (Boness et al. 1995, Proffitt et al. 2010), which might be facilitated by synchronized estrus. On the other hand, seals that attended reproductive colonies once before producing a pup, regardless of when that attendance took place, had nearly equal recruitment probability (e.g., $\hat{\psi}_{t, \text { age }}^{\mathrm{U1F}} \approx \hat{\psi}_{t, \mathrm{age}}^{\mathrm{PlF}}$ ), and for seals that did not attend in the year preceding recruitment, recruitment probabilities of experienced prebreeders were not greater than those for inexperienced prebreeders (i.e., $\hat{\psi}_{t \text {,age }}^{\mathrm{U} O \mathrm{~F}} \approx \hat{\psi}_{t, \text { age }}^{\mathrm{U} 2 \mathrm{~F}}<\hat{\psi}_{t \text {,age }}^{\mathrm{U} 1 \mathrm{~F}}$ ). Possible explanations for these seemingly conflicting results are that estrus synchrony might not be very important given that embryonic diapause can synchronize births (Boyd 1991) or a single year of attendance might adequately and permanently synchronize estrus. Also, a segment of the population that doesn't consistently attend colonies as prebreeders might be unlikely to ever recruit (Hadley et al. 2006). This latter explanation suggests fitness links to repeated TE and is consistent with the estimated state-dependent differences in recruitment probabilities, the slight increases in TE probabilities and decreases in recruitment probabilities for the oldest age class, and the fact that the mean number of years seals attended prior to recruitment was only $2.1 \mathrm{yr}$. A comparison of recruitment probabilities for state $\mathrm{U} 2$ and an additional state U3 for individuals seen three times or more could help evaluate a fitness hypothesis. However, we did not include state $\mathrm{U} 3$ because our data set included relatively few individuals that were ever in state U3, which made it unlikely that we could have gained important insights from such a complex model.

In our analysis, we assumed that females born in Erebus Bay typically return to Erebus Bay to mate and subsequently produce their first pup in Erebus Bay. However, some seals might mate in other areas or even at sea (de Bruyn et al. 2011) and/or subsequently recruit outside Erebus Bay. If that situation is common, then recruitment probabilities are underestimated, probably for all states, but perhaps especially so for unobservable states because they are most likely to have mated outside Erebus Bay. Recruitment outside Erebus Bay thus might be an alternative explanation for reduced recruitment probability at older ages and for state U2. However, several lines of evidence suggest that our assumptions are likely reasonable. First, as mentioned in Hadley et al. (2007), extensive searches during the pupping seasons of 1997-2000 throughout McMurdo Sound and beyond (although certainly not as intensive as surveys conducted in Erebus Bay) failed to find very many Erebus Bayborn females pupping outside Erebus Bay, even though substantial numbers of females were located without pups. Second, annual visits, albeit limited in duration and extent, during 2004-2013 to several large aggregations of females with young pups outside Erebus Bay that we thought might be used by animals born in Erebus Bay as alternate pup-rearing sites have repeatedly found minimal evidence of pupping outside of Erebus Bay by females born in Erebus Bay. Third, evidence of geographic variations in genetics and underwater vocalizations of Weddell seals suggests limited long-distance dispersal (Thomas and Stirling 1983, Davis et al. 2008). Fourth, although we did not include an analysis of reproductively active seals in this paper, there is strong evidence that most seals are faithful to colonies during years when they skip reproduction. Although prebreeders might not be as site faithful as breeders, site fidelity by breeders and skip-breeders at least suggests that fine-scale site fidelity is an important component of the life history of this population of Weddell seals.

Although uncertainty remains about events outside Erebus Bay, our findings on several sources of variability in TE probabilities and the consequences of colony attendance and nonattendance provide some support for previous suggestions that prebreeders trade off costs and benefits of attending colonies (Stauffer et al. 2013a). The balance of such trade-offs likely depends on annual environmental conditions, characteristics of individuals, and maybe population size, and may have strong implications for the age at first reproduction. Our understanding of mechanisms underlying hypothesized tradeoffs should improve as it becomes technologically feasible to monitor the movements of many individuals over relevant spatial and temporal scales.

Trade-offs related to TE and implications for future reproductive success likely are common among longlived colonial-breeding species. Evidence from Kittiwakes (Rissa tridactyla) suggests that prebreeding behavior and experience can influence short-term and long-term reproductive success and that recruitment at intermediate ages is optimal (Cam et al. 2002). An intermediate recruitment age also is optimal for future reproductive success of northern elephant seals (Mirounga angustirostrus; Reiter and Boeuf 1991). We focused our investigation on implications of annual attendance and nonattendence for age-specific recruitment probabilities. An interesting question we did not address was whether experienced prebreeders arrived earlier than inexperienced prebreeders (e.g., Pickering 1989, Dittmann and Becker 2003), and, given that prebreeders apparently trickled into Erebus Bay throughout the breeding season (Appendix A: Fig. A3), whether arrival date was related to future recruitment probability. Also, there appears to be considerable heterogeneity in long-term reproductive fitness among individual female Weddell seals following recruitment (Chambert et al. 2013), and it has been suggested that the highest quality individuals recruit at the youngest ages (Hadley et al. 2007). In the future, it would be useful to evaluate whether attendance patterns prior to recruitment might help explain heterogeneity in lifetime reproductive output.

\section{ACKNOWLEDGMENTS}

The National Science Foundation, Office of Polar Programs (grant no. ANT-0635739 to R. A. Garrott, J. J. Rotella, and D. B. Siniff, and previous grants to D. B. Siniff and J. W. Testa) 
funded our work. Raytheon Polar Services Corporation, Petroleum Helicopters International, and the New York National Guard provided logistical support, and many field assistants assisted with data collection. M. LaRue and C. Porter extracted data for sea-ice covariates. T. E. McMahon, D. B. Siniff, J. A. Schmutz, and two anonymous reviewers provided useful comments on previous manuscript drafts. Animal handling protocol was approved by Montana State University's Institutional Animal Care and Use Committee (Protocol \#41$05)$. Any use of trade, firm, or product names is for descriptive purposes only and does not imply endorsement by the U.S. Government.

\section{Literature Cited}

Balmford, A. 1991. Mate choice on leks. Trends in Ecology and Evolution 6:87-92.

Beauplet, G., C. Barbraud, M. Chambellant, and C. Guinet. 2005. Interannual variation in the post-weaning and juvenile survival of subantarctic fur seals: influence of pup sex, growth rate and oceanographic conditions. Journal of Animal Ecology 74:1160-1172.

Becker, P. H., and J. S. Bradley. 2007. The role of intrinsic factors for the recruitment process in long-lived birds. Journal of Ornithology 148:377-384.

Boness, D. J., W. D. Bowen, and S. J. Iverson. 1995. Does male harassment of females contribute to reproductive synchrony in the grey seal by affecting maternal performance? Behavioral Ecology and Sociobiology 36:1-10.

Boyd, I. L. 1991. Environmental and physiological factors controlling the reproductive cycles of pinnipeds. Canadian Journal of Zoology 69:1135-1148.

Burns, J. M. 1999. The development of diving behavior in juvenile Weddell seals: pushing physiological limits in order to survive. Canadian Journal of Zoology 77:737-747.

Burns, J. M., M. A. Castellini, and J. W. Testa. 1999. Movements and diving behavior of weaned Weddell seal (Leptonychotes weddellii) pups. Polar Biology 21:23-36.

Burns, J. M., S. J. Trumble, M. A. Castellini, and J. W. Testa. 1998. The diet of Weddell seals in McMurdo Sound, Antarctica as determined from scat collections and stable isotope analysis. Polar Biology 19:272-282.

Cadiou, B., J. Y. Monnat, and E. Danchin. 1994. Prospecting in the kittiwake, Rissa tridactyla: different behavioural patterns and the role of squatting in recruitment. Animal Behaviour 47:847-856.

Cam, E., B. Cadiou, J. E. Hines, and J. Y. Monnat. 2002. Influence of behavioural tactics on recruitment and reproductive trajectory in the kittiwake. Journal of Applied Statistics 29:163.

Cameron, M. F., D. B. Siniff, K. M. Proffitt, and R. A. Garrott. 2007. Site fidelity of Weddell seals: the effects of sex and age. Antarctic Science 19:149-155.

Castellini, M. A., G. L. Kooyman, and P. J. Ponganis. 1992. Metabolic rates of freely diving Weddell seals: correlations with oxygen stores, swim velocity and diving duration. Journal of Experimental Biology 165:181-194.

Chambert, T., J. J. Rotella, M. D. Higgs, and R. A. Garrott. 2013. Individual heterogeneity in reproductive rates and cost of reproduction in a long-lived vertebrate. Ecology and Evolution 3:2047-2060.

Davis, C. S., I. Stirling, C. Strobeck, and D. W. Coltman. 2008. Population structure of ice-breeding seals. Molecular Ecology 17:3078-3094.

de Bruyn, P. J. N., C. A. Tosh, M. N. Bester, E. Z. Cameron, T. McIntyre, and I. S. Wilkinson. 2011. Sex at sea: alternative mating system in an extremely polygynous mammal. Animal Behaviour 82:445-451.

Dittmann, T., and P. H. Becker. 2003. Sex, age, experience and condition as factors affecting arrival date in prospecting common terns, Sterna hirundo. Animal Behaviour 65:981986.
Dittmann, T., T. H. G. Ezard, and P. H. Becker. 2007. Prospectors' colony attendance is sex-specific and increases future recruitment chances in a seabird. Behavioural Processes 76:198-205.

Dugatkin, L. A., and J.-G. J. Godin. 1993. Female mate copying in the guppy (Poecilia reticulata): age-dependent effects. Behavioral Ecology 4:289-292.

Fernández-Juricic, E., and M. H. Cassini. 2007. Intra-sexual female agonistic behaviour of the South American sea lion (Otaria flavescens) in two colonies with different breeding substrates. Acta Ethologica 10:23-28.

Frederiksen, M., and T. Bregnballe. 2000. Diagnosing a decline in return rate of 1-year-old cormorants: mortality, emigration or delayed return? Journal of Animal Ecology 69:753-761.

Furness, R. W., and T. R. Birkhead. 1984. Seabird colony distributions suggest competition for food supplies during the breeding season. Nature 311:655-656.

Galef, B. G., Jr., and K. N. Laland. 2005. Social learning in animals: empirical studies and theoretical models. Bioscience 55:489-499.

Hadley, G. L., J. J. Rotella, and R. A. Garrott. 2007. Influence of maternal characteristics and oceanographic conditions on survival and recruitment probabilities of Weddell seals. Oikos 116:601-613.

Hadley, G. L., J. J. Rotella, R. A. Garrott, and J. D. Nichols. 2006. Variation in probability of first reproduction of Weddell seals. Journal of Animal Ecology 75:1058-1070.

Halley, D. J., M. P. Harris, and S. Wanless. 1995. Colony attendance patterns and recruitment in immature common murres (Uria aalge). Auk 112:947-957.

Handelmann, G., R. Ravizza, and W. J. Ray. 1980. Social dominance determines estrous entrainment among female hamsters. Hormones and Behavior 14:107-115.

Hill, S. E. B. 1987. Reproductive ecology of Weddell seals (Leptonychotes weddelli) in McMurdo Sound, Antartica. Dissertation. University of Minnesota, St. Paul, Minnesota, USA.

Hoffman, J. I., J. Forcada, P. N. Trathan, and W. Amos. 2007. Female fur seals show active choice for males that are heterozygous and unrelated. Nature 445:912-914.

Jenouvrier, S., G. Tavecchia, J.-C. Thibault, R. Choquet, and V. Bretagnolle. 2008. Recruitment processes in long-lived species with delayed maturity: estimating key demographic parameters. Oikos 117:620-628.

Kendall, W. L. 2004. Coping with unobservable and misclassified states in capture-recapture studies. Animal Biodiversity and Conservation 27:97-107.

Kendall, W. L., and R. Bjorkland. 2001. Using open robust design models to estimate temporary emigration from capture-recapture data. Biometrics 57:1113-1122.

Kooyman, G. L. 1966. Maximum diving capacities of the Weddell seal, Leptonychotes weddeili. Science 151:1553-1554.

Kwok, R. and J. C. Comiso. 2002. Southern Ocean climate and sea ice anomalies associated with the Southern Oscillation. Journal of Climate 15:487-501.

Laake, J. L. 2013. RMark: an R interface for analysis of capture-recapture data with MARK. AFSC processed report 2013-01. Alaska Fisheries Science Center, NOAA, National Marine Fisheries Service, Seattle, Washington, USA.

LaRue, M. A., J. J. Rotella, R. A. Garrott, D. B. Siniff, D. G. Ainley, G. E. Stauffer, C. C. Porter, and P. J. Morin. 2011. Satellite imagery can be used to detect variation in abundance of Weddell seals (Leptonychotes weddellii) in Erebus Bay, Antarctica. Polar Biology 34:1727-1737.

Loeb, V., V. Siegel, O. Holm-Hansen, R. Hewitt, W. Fraser, W. Trivelpiece, and S. Trivelpiece. 1997. Effects of sea-ice extent and krill or salp dominance on the Antarctic food web. Nature 387:897-900.

Long, E. S., D. R. Diefenbach, C. S. Rosenberry, and B. D. Wallingford. 2008. Multiple proximate and ultimate causes 
of natal dispersal in white-tailed deer. Behavioral Ecology 19 $1235-1242$.

Madsen, T., and R. Shine. 2000. Silver spoons and snake body sizes: prey availability early in life influences long-term growth rates of free-ranging pythons. Journal of Animal Ecology 69:952-958.

Matthysen, E. 2005. Density-dependent dispersal in birds and mammals. Ecography 28:403-416.

McCann, T. S. 1982. Aggressive and maternal activities of female southern elephant seals (Mirounga leonina). Animal Behaviour 30:268-276.

McClintock, M. K. 1978. Estrous synchrony and its mediation by airborne chemical communication (Rattus norvegicus). Hormones and Behavior 10:264-276.

Pickering, S. P. C. 1989. Attendance patterns and behaviour in relation to experience and pair-bond formation in the wandering albatross Diomedea exulans at South Georgia. Ibis 131:183-195.

Pitman, R. L., and J. W. Durban. 2012. Cooperative hunting behavior, prey selectivity and prey handling by pack ice killer whales (Orcinus orca), type B, in Antarctic Peninsula waters. Marine Mammal Science 28:16-36.

Proffitt, K. M., R. A. Garrott, J. J. Rotella, D. B. Siniff, and J. W. Testa. 2007. Exploring linkages between abiotic oceanographic processes and a top-trophic predator in an Antarctic ecosystem. Ecosystems 10:120-127.

Proffitt, K. M., J. J. Rotella, and R. A. Garrott. 2010. Effects of pup age, maternal age, and birth date on pre-weaning survival rates of Weddell seals in Erebus Bay, Antarctica. Oikos 119:1255-1264.

R Development Core Team. 2012. R: a language and environment for statistical computing. R Foundation for Statistical Computing, Vienna, Austria. http://www. r-project.org

Reed, J. M., T. Boulinier, E. Danchin, and L. W. Oring. 1999. Informed dispersal: prospecting by birds for breeding sites. Current Ornithology 15:189-259.

Reiter, J., and B. J. Le Boeuf. 1991. Life history consequences of variation in age at primiparity in northern elephant seals. Behavioral Ecology and Sociobiology 28:153-160.

Rotella, J. J., W. A. Link, J. D. Nichols, G. L. Hadley, R. A. Garrott, and K. M. Proffitt. 2009. An evaluation of densitydependent and density-independent influences on population growth rates in Weddell seals. Ecology 90:975-984.

Schafer, J. L. 1999. Multiple imputation: a primer. Statistical Methods in Medical Research 8:3-15.

Siniff, D. B., D. P. DeMaster, R. J. Hofman, and L. L. Eberhardt. 1977. An analysis of the dynamics of a Weddell seal population. Ecological Monographs 47:319-335.
Smith, M. S. R. 1965. Seasonal movements of the Weddell seal in McMurdo Sound, Antarctica. Journal of Wildlife Management 29:464-470.

Smith, M. S. R. 1966. Studies of the Weddell seal (Leptonychotes weddelli Lesson) in McMurdo Sound, Antarctica. Dissertation. University of Caterbury, Christchurch, New Zealand.

Stauffer, G. E., J. J. Rotella, and R. A. Garrott. $2013 a$. Variability in temporary emigration rates of individually marked female Weddell seals prior to first reproduction. Oecologia 172:129-140.

Stauffer, G. E., J. J. Rotella, and R. A. Garrott. 2013b. Birthyear and current-year influences on survival and recruitment rates of female Weddell seals. Population Ecology 55:405415.

Stern, K., and M. K. McClintock. 1998. Regulation of ovulation by human pheromones. Nature 392:177-179.

Stewart, B., P. Yochem, T. Gelatt, and D. Siniff. 2000. Firstyear movements of Weddell seal pups in the Western Ross Sea, Antarctica. Pages 71-76 in W. Davidson, C. HowardWilliams, and P. Broady, editors. Antarctic ecosystems: models for wider ecological understanding. Proceedings of the 7th SCAR Symposium on Antarctic Biology, Christchurch, New Zealand.

Stirling, I. 1969. Ecology of the Weddell seal in McMurdo Sound, Antarctica. Ecology 50:573-586.

Testa, J. W., G. Oehlert, D. G. Ainley, J. L. Bengtson, D. B. Siniff, R. M. Laws, and D. Rounsevell. 1991. Temporal variability in Antarctic marine ecosystems - periodic fluctuations in the Phocid seals. Canadian Journal of Fisheries and Aquatic Sciences 48:631-639.

Testa, J. W., D. B. Siniff, M. J. Ross, and J. D. Winter. 1985. Weddell seal-Antarctic cod interactions in McMurdo Sound. Pages 561-565 in W. R. Siegfried, P. R. Condy, and R. M. Laws, editors. Antarctic nutrient cycles and food webs. Proceedings of the 4th SCAR symposium on Antarctic biology, Springer, New York, New York, USA.

Thomas, J. A., and I. Stirling. 1983. Geographic variation in the underwater vocalizations of Weddell seals (Leptonychotes weddelli) from Palmer Peninsula and McMurdo Sound, Antarctica. Canadian Journal of Zoology 61:2203-2212.

Valone, T. 2007. From eavesdropping on performance to copying the behavior of others: a review of public information use. Behavioral Ecology and Sociobiology 62:1-14.

Wartzok, D. 1991. Physiology of behavior in pinnipeds. Pages 236-299 in D. Renouf, editor. Behavior of pinnipeds. Chapman and Hall, New York, USA.

White, G. C., and K. P. Burnham. 1999. Program MARK: survival estimation from populations of marked animals. Bird Study 46(Supplement):120-138.

\section{Supplemental Material}

\section{Appendix A}

Details of open robust-design multistate (ORDMS) modeling, and estimates for survival and within-season parameters (Ecological Archives E095-222-A1). 